\title{
Are current fibre recommendations using NSP adequate? A comparison of Englyst and Association of Official Analytical Chemists fibre values
}

\author{
M. Aldwairji, V. Burley and C. Orfila \\ School of Food science and Nutrition, University of Leeds, Leeds LS2 9JT, UK
}

The current UK recommendation for dietary fibre intake of $18 \mathrm{~g} / \mathrm{d}$ is based on NSP as determined by the analytical method by Englyst ${ }^{(1)}$. In the US and most European countries, dietary fibre recommendations are based on determinations using the enzymatic gravimetric method by the Association of Official Analytical Chemists (AOAC) ${ }^{(2)}$. The food industry is increasingly using AOAC fibre values for nutritional labels. Is it therefore time to revise current UK recommendations to be based on AOAC values? For recommendations to be revised, epidemiological studies linking fibre intake to health outcomes would need to be reassessed using AOAC data. One barrier to this approach is the lack of AOAC data in the McCance and Widdowson's The Composition of Foods database ${ }^{(3)}$. Some information exists between the relationship of NSP and AOAC values for some food groups ${ }^{(3)}$, with a general correlation of AOAC $=1.3098 \times \mathrm{NSP}+0.082$. However, very little information is available for the legume group. Here we present a comparison of NSP and experimentally determined AOAC values for insoluble dietary fibre (IDF) for selected legume samples (see table below). The AOAC method was adapted for the legume samples to include an efficient starch gelatinisation step (autoclaving at $126^{\circ} \mathrm{C}, 60 \mathrm{~min}$ ) prior to digestion with thermostable alphaamylase as described by $\mathrm{Li}^{(4)}$.

\begin{tabular}{lccc}
\hline Legumes (raw) & $\begin{array}{c}\text { Mean experimental } \\
\text { IDF by AOAC }\end{array}$ & $\begin{array}{c}\text { Mean IDF by } \\
\text { Englyst }^{(3)}\end{array}$ \\
\hline Whole chickpeas $(n)$ & 22 & 1.25 & 7.4 \\
Split chickpeas & 9.045 & 2.55 & $N^{*}$ \\
Haricot beans & 7.02 & 0.84 & 9.1 \\
Red kidney beans & 6.445 & 0.24 & 8.8 \\
Green/brow lentils & 10.555 & 0.22 & 6.9 \\
Black-eyed beans & 7.06 & 0.27 & 5.3 \\
Red split lentils & 13.91 & 4.34 & 3.6 \\
Mung beans & 12.7 & 0.67 & 7.2 \\
Split green peas & 3.55 & 0.40 & 3.5 \\
\hline$* N$ Nutrient present in significant quantity but there is no reliable information on the amount
\end{tabular}

The results indicated that for most legumes, the AOAC IDF values were higher than IDF values by the Englyst method. This was expected due to the inclusion of a larger proportion of insoluble material such as resistant starch and lignin in AOAC IDF. However, for some legumes (e.g. red kidney beans and haricot beans), the experimental AOAC IDF values were lower than Englyst. This has been previously observed for some foods ${ }^{(3)}$ and requires further investigation. The revision of fibre recommendations using AOAC may not be a straight forward process.

1. AOAC (1995) Official Methods of Analysis, 16th ed. AOAC International, Gaithersburg, MD, 1995.

2. Englyst H, Wiggins HS \& Cummings JH (1982) Analyst 107, 307-318.

3. Food Standard Agency (2006) McCannce and Widdowson's The Composition of Foods, Sixth Summary Edition. Cambridge: Royal Society of Chemistry.

4. Li BW \& Zhao Z (1997) J Agric Food Chem 45, 2598-2601. 